\title{
Two Cases of Acute Abdomen after an Intravitreal Injection of Bevacizumab
}

\author{
Yasutaka Onoda ${ }^{a} \quad$ Tomoaki Shiba $^{c}$ Yuichi Horic ${ }^{c}$ Takatoshi Maeno ${ }^{a}$ \\ Mao Takahashib \\ ${ }^{\mathrm{a}}$ Department of Ophthalmology, and ${ }^{\mathrm{b}}$ Cardiovascular Center, Toho University Sakura \\ Medical Center, Chiba, and 'Department of Ophthalmology, Toho University School of \\ Medicine, Tokyo, Japan
}

\section{Key Words}

Intravitreal injection of bevacizumab $\cdot$ Acute abdomen $\cdot$ Side effect $\cdot$ Vascular endothelial growth factor · Ischemic colitis · Paralytic ileus

\begin{abstract}
We report on a patient with ischemic colitis and another with paralytic ileus, both of whom experienced an acute abdomen after intravitreal injection of bevacizumab (IVB). Case 1 was a 78-year-old woman. Her medical history included surgery for colon carcinoma 10 years earlier. The patient developed acute severe abdominal pain and nausea the day after IVB for retinal vein occlusion with macular edema, and massive lower gastrointestinal bleeding occurred. Ischemic colitis was diagnosed. Case 2 was a 64 -year-old man who presented with neovascular glaucoma with proliferative diabetic retinopathy. We performed vitreous surgery on the 9th day after IVB, and we reperformed IVB at the end of the vitreous surgery. On the first postoperative day, severe abdominal distension, vomiting and abdominal pain were observed, and paralytic ileus was diagnosed. It is possible that gastrointestinal disorders are induced after IVB, depending on the patient's background, including for example severe diabetes or a history of surgery for gastrointestinal cancer. Thus, ophthalmologists should apply alternative therapies instead of IVB to patients with severe diabetes mellitus or a history of gastrointestinal cancer.


Onoda et al.: Two Cases of Acute Abdomen after an Intravitreal Injection of Bevacizumab

\section{Introduction}

Intravitreal injections of vascular endothelial growth factor (VEGF) inhibitors for exudative age-related macular degeneration (AMD), diabetic retinopathy, neovascular glaucoma and retinal vein occlusions are becoming the most frequent procedures in ophthalmology. In the randomized Comparison of Age-Related Macular Degeneration Treatments Trials (CATT) that assessed the relative efficacy and safety of ranibizumab (Lucentis, Novartis Pharma, Basel, Switzerland, and Genentech, South San Francisco, Calif., USA) and bevacizumab (Avastin, Genentech) for exudative AMD treatment, the incidence rates of serious systemic adverse events were higher in the bevacizumab-treated patients than in the ranibizumabtreated patients; in particular, the occurrence of gastrointestinal disorders was significantly higher with bevacizumab $(3.0 \%)$ than with ranibizumab $(1.0 \%)$ [1]. The major systemic adverse side effects of intravenous bevacizumab that have been identified in patients with cancer are hypertension [2, 3], protein urea [2-4], arterial thrombotic events $[3,4]$ and gastrointestinal perforation [4]. Here, we describe two cases of an acute abdomen after intravitreal injection of bevacizumab (IVB). All patients provided informed consent according to the Declaration of Helsinki, and the patients/next of kin/guardians have consented to the submission of this case report.

\section{Case Report}

Case 1

A 78-year-old Japanese woman presented with central retinal vein occlusion with refractory macular edema. Her medical history included surgery for colon carcinoma 10 years earlier and controlled diabetes mellitus. The patient had been hospitalized three times since the colon carcinoma surgery due to postoperative ileus and ischemic colitis but had not had a recurrence over the past few years. She had no history or sign of stroke or coronary artery disease. IVB $(1.25 \mathrm{mg} / 0.05 \mathrm{ml})$ was performed for refractory macular edema. On the first day after IVB, the patient developed acute severe abdominal pain and nausea, and massive lower gastrointestinal bleeding occurred. She was taken to the emergency room of a different hospital, and recurrence of ischemic colitis was diagnosed.

She was hospitalized the same day and treated by intravenous fluid replacement, and oral intake was terminated. Three days after IVB, her hemoglobin was $11.4 \mathrm{~g} / \mathrm{dl}$, her hematocrit 33.5\% and her C-reactive protein (CRP) $9.3 \mathrm{mg} / \mathrm{l}$.

The patient's ischemic colitis had improved on the 9th day of admission, without surgery.

Case 2

A 64-year-old Japanese man presented with uncontrolled intraocular pressure (IOP) due to neovascular glaucoma with proliferative diabetic retinopathy. IOP in the left eye was $30 \mathrm{~mm} \mathrm{Hg}$. A prominent iris and angle neovascularization and moderate vitreous hemorrhage were recognized in the left eye. Panretinal photocoagulation had not been performed. His medical history included diabetes mellitus diagnosed 15 years earlier and controlled hypertension. There was no history of stroke, coronary artery disease or gastrointestinal disorder. IVB (1.25 mg/0.05 ml) was performed for neovascular glaucoma. Two days later, the patient experienced nausea and abdominal pain, but he did not seek treatment for it, and therefore, we could not confirm it. Because the IOP could not be controlled and the vitreous hemorrhage was not absorbed, we performed vitreous surgery on the 9th day after IVB, and 
Onoda et al.: Two Cases of Acute Abdomen after an Intravitreal Injection of Bevacizumab

we reperformed IVB $(1.25 \mathrm{mg} / 0.05 \mathrm{ml})$ at the end of the vitreous surgery. On the first postoperative day, severe abdominal distension, vomiting and abdominal pain were observed. An upright abdominal X-ray demonstrated excess air and niveau in the intestine (fig. 1). A CT coronal scan revealed prominent dilated and air-filled images of the intestinal wall, without apparent lesions (fig. 2). Paralytic ileus was diagnosed. The laboratory profile on the first postoperative day was as follows: glycosylated hemoglobin $\mathrm{A}_{1 \mathrm{C}}$ 5.9\%, CRP $15.5 \mathrm{mg} / \mathrm{l}$, creatinine $3.59 \mathrm{mg} / \mathrm{dl}$, blood urea nitrogen $78.7 \mathrm{mg} / \mathrm{dl}$ and hemoglobin $10.9 \mathrm{~g} / \mathrm{dl}$. Paralytic ileus had improved after conservative treatment with ileus tubing by the 24 th day of admission, without surgery.

\section{Discussion}

Gastrointestinal perforation is one of the intravenous bevacizumab-associated gastrointestinal disorders. It is a serious adverse event which in rare cases has resulted in death. Gastrointestinal perforation has been observed in patients with various malignancies with a documented incidence in clinical trials ranging from 0.9 to $5 \%$ [5].

There was a previous report of an 88-year-old woman with macular degeneration on long-term IVB who presented with acute gastrointestinal hemorrhage [6]. The reasons for the development of bevacizumab-associated gastrointestinal perforation are not clear [7]; however, it was reported that bowel obstruction or ileus may be associated with an increased risk of intravenous bevacizumab-associated gastrointestinal perforation [8]. Our case 1 had some risk factors for gastrointestinal perforation: a history of surgery for colon carcinoma, postoperative ileus and ischemic colitis. In contrast, case 2 did not have any risk factors, but he had severe diabetes mellitus.

We propose the following reasons for the development of a gastrointestinal disorder after IVB. It was found that a single IVB significantly reduced the plasma VEGF levels for up to 1 month compared to no significant systemic effects of an intravireal injection of ranibizumab on plasma VEGF in patients with diabetic macular edema and AMD [9]. In addition, Matsuyama et al. [10] reported that the plasma VEGF level decreased markedly as early as 1 day after IVB in patients with diabetic retinopathy. In light of these findings, it is possible that systemic side effects can develop after IVB as well as after intravenous bevacizumab.

Decreased plasma VEGF resulted in the decreased production of nitric oxide [11], a known vasodilator. Therefore, decreased VEGF production can cause vasoconstriction and reduce the supply of gastrointestinal blood flow. We speculate that these factors may trigger a gastrointestinal disorder after IVB. Because our two cases did not have another episode of systemic events responsible for the gastrointestinal disorder, we suspect that IVB directly induced the recurrence of ischemic colitis and paralytic ileus.

In conclusion, we report on a patient with ischemic colitis and another with paralytic ileus, both of whom experienced an acute abdomen after IVB. It is possible that gastrointestinal disorders are induced after IVB, depending on the patient's background, including for example severe diabetes or a history of surgery for gastrointestinal cancer.

Ophthalmologists should apply alternative therapies instead of IVB to patients with severe diabetes mellitus or a history of gastrointestinal cancer as shown in our two cases.

\section{Disclosure Statement}

The authors have no proprietary or financial interest regarding any aspect of this report. 
Onoda et al.: Two Cases of Acute Abdomen after an Intravitreal Injection of Bevacizumab

\section{References}

$>1$ CATT Research Group, Martin DF, Maguire MG, Ying GS, Grunwald JE, Fine SL, Jaffe GJ: Ranibizumab and bevacizumab for neovascular age-related macular degeneration. N Engl J Med 2011;364:1897-1908.

-2 Kabbinavar F, Hurwitz HI, Fehrenbacher L, Meropol NJ, Novotny WF, Lieberman G, Griffing S, Bergsland E: Phase II, randomized trial comparing bevacizumab plus fluorouracil (FU)/leucovorin (LV) with FU/LV alone in patients with metastatic colorectal cancer. J Clin Oncol 2003;21:60-65.

-3 Kabbinavar FF, Schulz J, McCleod M, Patel T, Hamm JT, Hecht JR, Mass R, Perrou B, Nelson B, Novotny WF: Addition of bevacizumab to bolus fluorouracil and leucovorin in first-line metastatic colorectal cancer: results of a randomized phase II trial. J Clin Oncol 2005;23:3697-3705.

-4 Hurwitz H, Fehrenbacher L, Novotny W, Cartwright T, Hainsworth J, Heim W, Berlin J, Baron A, Griffing S, Holmgren E, Ferrara N, Fyfe G, Rogers B, Ross R, Kabbinavar F: Bevacizumab plus irinotecan, fluorouracil, and leucovorin for metastatic colorectal cancer. N Engl J Med 2004;350:2335-2342.

5 Badgwell BD, Camp ER, Feig B, Wolff RA, Eng C, Ellis LM, Cormier JN: Management of bevacizumabassociated bowel perforation: a case series and review of the literature. Ann Oncol 2008;19:577-582.

-6 Pepper AN, Valenzuela MO, Oller KL: Aortoduodenal fistula in a patient on intravitreal bevacizumab injections: a case report. Am J Ther 2014, Epub ahead of print.

7 Saif MW, Elfiky A, Salem RR: Gastrointestinal perforation due to bevacizumab in colorectal cancer. Ann Surg Oncol 2007;14:1860-1869.

8 Tanyi JL, McCann G, Hagemann AR, Coukos G, Rubin SC, Liao JB, Chu CS: Clinical predictors of bevacizumabassociated gastrointestinal perforation. Gynecol Oncol 2011;120:464-469.

-9 Zehetner C, Kirchmair R, Huber S, Kralinger MT, Kieselbach GF: Plasma levels of vascular endothelial growth factor before and after intravitreal injection of bevacizumab, ranibizumab and pegaptanib in patients with age-related macular degeneration, and in patients with diabetic macular oedema. Br J Ophthalmol 2013;97:454-459.

10 Matsuyama K, Ogata N, Matsuoka M, Wada M, Takahashi K, Nishimura T: Plasma levels of vascular endothelial growth factor and pigment epithelium-derived factor before and after intravitreal injection of bevacizumab. Br J Ophthalmol 2010;94:1215-1218.

11 Hood JD, Meininger CJ, Ziche M, Granger HJ: VEGF upregulates ecNOS message, protein, and NO production in human endothelial cells. Am J Physiol 1998;274:H1054-H1058.

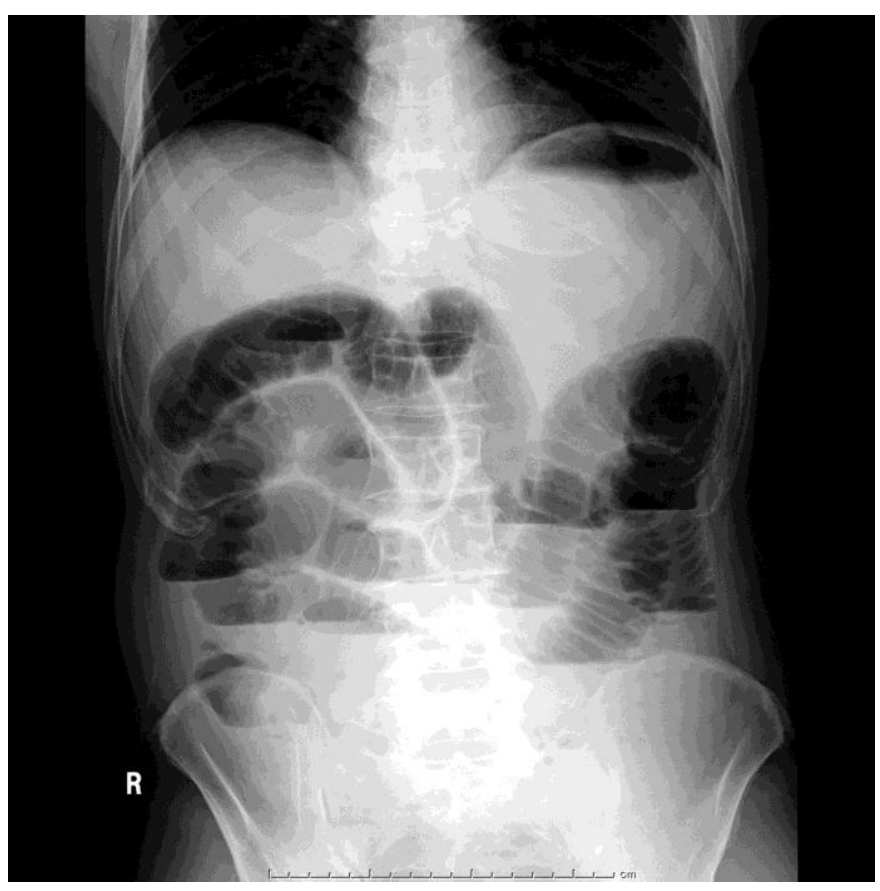

Fig. 1. Upright abdominal X-ray of case 2, a male 64-year-old Japanese. Excess air and niveau in the intestine were revealed. 
Case Reports in

Ophthalmology
Case Rep Ophthalmol 2015;6:110-114

DOI: $10.1159 / 000381257$

Onoda et al:

Bevacizumab

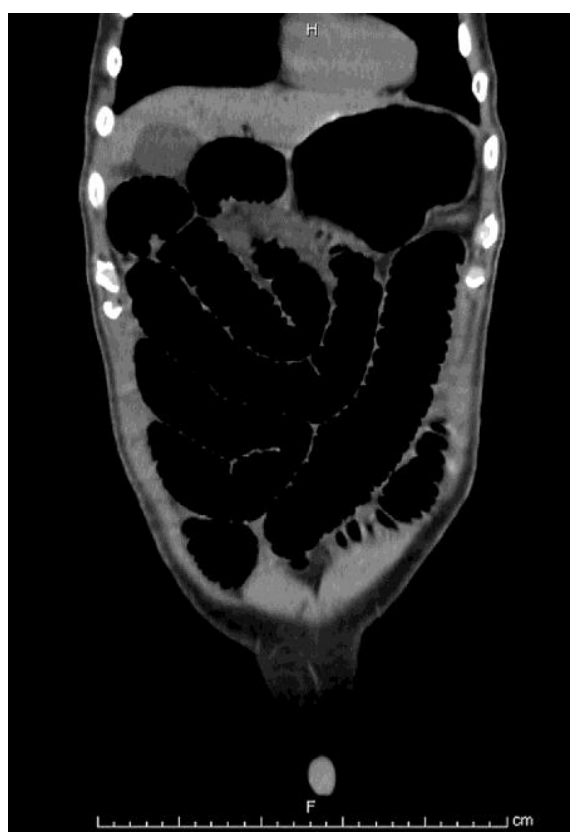

Fig. 2. CT coronal scan of case 2. Prominent dilated and air-filled images of the intestinal wall without apparent lesions were revealed. 